\title{
Estimation of leaf water content and specific leaf weight from reflectance and transmittance measurements
}

\author{
F Baret*, T Fourty \\ Station de bioclimatologie, Inra, site Agroparc, 84914 Avignon cedex 9, France
}

(Received 30 September 1997; accepted 6 january 1998)

\begin{abstract}
Summary - Specific absorption coefficients for water and dry matter were estimated using a wide range of variation of fresh leaves. The coefficients were derived from the inversion of the PROSPECT leaf optical property model using reflectance and transmittance spectra measured over the 1300-2 400-nm domain and the corresponding water content $\left(\mathrm{g} . \mathrm{cm}^{-2}\right)$ and specific leaf weight (mass of dry matter per unit leaf.area, $\mathrm{g} . \mathrm{cm}^{-2}$ ). Results show that the estimated values of the specific absorption coefficient for dry matter were not reliable in the strong water absorption bands, although there was agreement with previous studies in spectral regions where water contributed moderately to leaf absorption. We thus proposed to use the values derived by Fourty et al (1996) for dry leaves for the specific absorption coefficient of dry matter. Estimated values of the specific absorption coefficient of water were slightly higher than the values proposed by Curcio and Petty (1951) for pure water. We then investigated the possibility of estimating leaf water content and specific weight by inverting the PROSPECT model using concurrently or separately reflectance and/or transmittance spectra measured over fresh leaves and the specific absorption coefficients proposed by Fourty et al (1996) for dry matter, and Curcio and Petty (1951) for water. Results obtained on the training data set and on an independent data set show accurate and robust estimates of both water content $\left(\mathrm{RMSE}=0.0025 \mathrm{g.cm}{ }^{-2}\right)$ and specific leaf weight

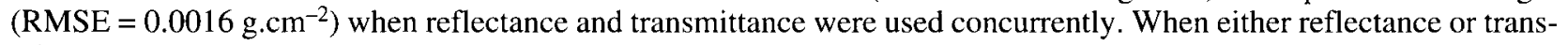
mittance measurements were used, the performances of water and dry matter content estimation decreased because of the relaxation of constraints in the inversion process. Possible applications of these results are discussed.
\end{abstract}

reflectance / transmittance / leaf / model inversion / specific absorption coefficient / water content / specific leaf weight

Résumé - Estimation du contenu en eau et de la masse sèche surfacique des feuilles à partir de spectres de réflectance et de transmittance. Les coefficients spécifiques de l'eau et de la matière sèche sont estimés en inversant le modèle Prospect de propriétés optiques des feuilles sur une collection variée de feuilles fraîches sur lesquelles les contenus en eau (g.cm ${ }^{-2}$ ), les masses sèches surfacique (masse de matière sèche par unité de surface de feuille, g.cm ${ }^{-2}$ ) et les spectres de réflectance et transmittance dans le domaine 1300-2 $400 \mathrm{~nm}$ ont été mesurés. Les résultats montrent que les valeurs estimées du coefficient d'absorption spécifique de la matière sèche ne sont pas fiables dans les bandes de forte absorption par l'eau, alors qu'en dehors de ces bandes, un bon accord est observé avec les résultats antérieurs. Nous proposons donc d'utiliser les valeurs de coefficient spécifique d'absorption de Fourty et al (1996) calculées sur des feuilles sèches. Les valeurs estimées du coefficient spécifique d'absorption de l'eau sont légèrement surestimées

Article communicated by Gérard Guyot (Avignon)

* Correspondence and reprints

Tel: (33) 04903160 82; fax: (33) 04908998 10; e-mail: baret@avignon.inra.fr 
par rapport aux valeurs proposées par Curcio et Petty (1951). Nous avons ensuite évalué la possibilité d'estimer le contenu en eau et la masse sèche surfacique en inversant le modèle Prospect en utilisant des spectres de réflectance et/ou de transmittance mesurés sur des feuilles frâiches, avec les coefficient spécifiques proposés par Fourty et al pour la matière sèche ou par Curcio et Petty pour l'eau. Les résultats obtenus sur le jeu d'apprentissage et un jeu de données indépendant montrent une bonne estimation du contenu en eau (RMSE $=0,0016 \mathrm{~g} . \mathrm{cm}^{-2}$ ) et de la masse surfacique sèche $\left(\mathrm{RMSE}=0,0016 \mathrm{~g} \cdot \mathrm{cm}^{-2}\right)$ quand la réflectance et la transmittance sont utilisées simultanément. En revanche, quand la réflectance ou la transmittance est utilisée seule, la précision des estimations diminue significativement du fait de la réduction des contraintes imposées au processus d'inversion. Les applications possibles de ces résultats sont discutées.

réflectance / transmittance / feuille / inversion de modèle / coefficient d'absorption spécifique /contenu en eau / masse sèche surfacique

\section{INTRODUCTION}

Remote sensing techniques allow the continuous monitoring of vegetation over large areas. They can provide biophysical and biochemical characteristics of canopies that could help us describe and understand ecosystems functioning. Since Peterson et al (1988) several experimental results showed statistical correlations between canopy biochemical composition and the corresponding reflectance spectra recorded by spectro-imaging systems (Wessman et al, 1988; Smith and Curran, 1992; Martin and Aber, 1993, 1994; Zagolsky, 1994; Gastellu-Etchegorry et al, 1995, Dawson et al, 1996; Gholz et al, 1996; Jacquemoud et al, 1996; Curran et al, 1997). However, recent developments have demonstrated that the relationships elaborated on one site had very poor predictive performances when applied to another site or even to another year (NASA, 1994; Grossman et al, 1996). Therefore, questions arise about the actual causal relations between variation in canopy biochemical composition and reflectance spectra observed at canopy, airborne, or indeed satellite levels. Fourty et al (1996) used a leaf optical property model to investigate leaf absorption in relation to its biochemical composition. This physical approach allows us to explain leaf absorption as a function of its biochemical composition, including cellulose, hemicellulose, lignin, starch and protein. However, the absorption signals corresponding to each of these biochemical compounds are too weak and not specific enough to allow accurate biochemical composition retrieval from leaf optical property spectra when applied to a broad range of leaf types. The only biochemical variables that could be reliably estimated from leaf reflectance or transmittance spectra were the total mass per unit area (namely, the specific leaf weight, or dry matter content) and the water content (Fourty et al, 1996). These findings were derived from almost dry leaves. In this paper, we will investigate how these results can be transferred to fresh leaves and validate the results on an independent data set. Estimates of leaf specific weight and water content are interesting at leaf level because it is the first step before investigating the problem of retrieving leaf characteristics from canopy or satellite level observations. Further, it provides a tool to develop in-situ nondestructive measurements of leaf characteristics for ecophysiological studies.

The specific leaf weight (SLW, g.cm-2) and its reciprocal, the specific leaf area (SLA, $\left.\mathrm{cm}^{2} \cdot \mathrm{g}^{-1}\right)$, are key variables involved with or related to physiological processes occurring in the functioning of canopies. The specific leaf area directly governs the change in leaf area index (LAI, $\mathrm{m}^{2} \cdot \mathrm{m}^{-2}$ ), through the building of new leaf area from freshly allocated assimilates. The specific leaf weight is very sensitive to plant nitrogen status, light climate and several other stresses (Field and Mooney, 1986). Thus, the estimation of this variable is very important. Little literature is devoted to this subject. However, leaf dry mass is very strongly correlated to carbon content, carbon atoms being obviously widely used in any living tissue; Grossman et al (1996) showed for example a strong correlation between carbon content and leaf reflectance or transmittance.

Leaf water content is generally not considered as a driving variable in canopy functioning models. For example, small to moderate water stress generally does not change leaf water content by very much (Beaumont, 1995). However this variable can be derived from canopy functioning models and can be used in data assimilation strategies to force canopy functioning models to match actual remote sensing observations, with particular attention to the leaf area index dynamics. Few studies have attempted to relate leaf reflectance or transmittance spectra to leaf water content. Thomas et al (1971), Hunt et al (1987) and Hunt and Rock (1989) correlated the relative water con- 
tent (RWC) to leaf reflectance in the 1300-2 400$\mathrm{nm}$ spectral domain. Leaf relative water content is the actual leaf water content relative to the leaf water content at full turgescence. The relationships were fitted using several types of leaves, ranging from succulent to low water content leaves and provided good performances. However, the results were not evaluated on other independent data sets to test their predictive performances. Further, the relative water content is not a variable directly or physically linked to the absorption processes, and thus to reflectance or transmittance. Therefore, it will not be surprising to observe that no universal and robust relationship exists between RWC and leaf reflectance or transmittance. Allen et al (1969) and Tucker (1980) proposed the use of the leaf water content or equivalent water thickness to describe the absorption in the 1 300-2 400-nm spectral domain. This variable is the one that is physically related to the absorption processes because it is a measure of the optical path.

Jacquemoud and Baret (1990) and Jacquemoud et al (1996) used another approach through the inversion of a simple leaf optical property model. They demonstrated the feasibility of the estimation of leaf water content from the inversion of the PROSPECT model over fresh leaf reflectance and transmittance spectra.

This study will focus on the estimation of both specific leaf weight and water content from fresh leaf reflectance or transmittance spectra. We will attempt to derive a physical model that explicitly takes into account water and dry matter absorption features. This will be achieved using the PROSPECT model in the same way as for the detailed biochemical composition within the 1 300-2 400-nm spectral domain (Fourty et al, 1996). Then, we will evaluate the performances of model inversion for leaf water content and specific leaf weight estimation. We will first present the data set used to derive the specific absorption coefficients for water and dry matter, and then invert the model.

\section{THE DATA SETS}

We used two independent data sets. One is primarily used to calibrate the model. The other is used to evaluate the performances of the model in its inverse mode for the estimation of leaf water content and specific weight. We will restrict the study to the $1300-2$ 400-nm spectral domain where water absorbs the most. Further it provides consistency with previous work carried out on dry leaves for the estimation of the biochemical composition (Fourty et al, 1996). The specific absorption coefficients estimated by Fourty et al (1996) were only computed in the 1300-2 400-nm spectral domain. Brown pigments (polyphenols) absorbing at wavelengths below $1300 \mathrm{~nm}$ appeared during the drying process of the leaves, and consequently, reliable values of the specific absorption coefficients were not possible for the dry matter below $1300 \mathrm{~nm}$.

\section{Training data set}

Fifty-eight leaf types representing a wide range of species and physiological statuses were collected. They include dicotyledone, monocotyledone, annual and perennial plants, trees and herbaceous species (Hosgood et al, 1995): Acer pseudoplatanus, Alnus glutinosa, Armeniaca vulgaris, Betula alba, Brassica oleracera, Castanea sativa, Corylus avellana, Fagus sylvatica, Ficus carica, Fraxinus excelsior, Hedera helix, Helianthus annuus, Juglans regia, Laurus nobilis, Lycopersicon eculentum, Medicago sativa, Morus alba, Morus nigra, Populus canadiensus, Populus tremula, Prunus laurocerasus, Prunus serotina, Quercus pubescens, Robinia pseudoacacia, Salix alba, Salvia officinalis, Soja hispida, Solanum tuberosum, Tilia europaea, Trifolium pratense, Ulmus gabra, Urtica dioica, Vitis sivestris, Vitis vinifera, Bambusa acundinacea, Musa ensete, Oryza sativa, Phleum pratense, Phragmites communis, Sorghum halepense and Zea mays. Reflectance and transmittance measurements were performed in the 1300-2 500-nm range using a Perkin-Elmer spectrophotometer equipped with an integrating sphere. This type of measurement configuration minimises problems related to the nonlambertian properties of plant leaves. This instrument provided a spectral resolution around $2 \mathrm{~nm}$ depending on the wavelength, with a 1-nm sampling interval. However, to compress the data set, we resampled each spectrum every $10 \mathrm{~nm}$. The output signal was calibrated into absolute directional/hemispherical reflectance or transmittance using spectralon references. The reflectance and transmittance of five leaves for each leaf type were acquired and then averaged after calibration. The radiometric noise was very small, close to $0.05 \%$ of the signal. The area of the leaves was measured. The water content was evaluated after drying the samples at $85{ }^{\circ} \mathrm{C}$ for $48 \mathrm{~h}$. Both dry matter and water mass were expressed per unit fresh leaf area. This resulted in the specific leaf 
weight $\left(\mathrm{g} \cdot \mathrm{cm}^{-2}\right)$ and water content also called equivalent water thickness $\left(\mathrm{g} \cdot \mathrm{cm}^{-2}=\mathrm{cm}^{3} \cdot \mathrm{cm}^{-2}=\right.$ $\mathrm{cm})$. In the following, specific leaf weight and water content will be noted, respectively, by SLW and $C_{\mathrm{w}}$. The range and the average biochemical composition are presented in table I. Almost no correlation between the contents of water and dry matter was observed.

\section{Validation data set}

Twenty-two leaf types corresponding also to a wide range of species and physiological statuses were collected. They include Zea mays, Triticum aestivum, Lycopersicon esculentum, Glycine max, Helianthus annuus, Quercus robur, Acer negundo and Othonopsis cheiriifolia. Reflectance and transmittance measurements were performed in the 1300-2 500-nm range using a Varian Cary 17 DI spectrophotometer equipped with an integrating sphere. This instrument provided a spectral resolution of approximately $2 \mathrm{~nm}$, with a sampling interval of $17 \mathrm{~nm}$. The output signal was calibrated into absolute directional-hemispherical reflectance and transmittance using a $\mathrm{BaSO}_{4}$ reference panel. The reflectance and transmittance of five leaves for each leaf type were measured and then averaged after calibration. The radiometric noise was close to 0.01 , ie, about twice that of the training data set. The water content and specific leaf weight were measured using the same methodology as that used for the training data set. The average values obtained on the validation data set are presented in table $I$.

\section{MODELLING FRESH LEAF OPTICAL PROPERTIES}

This part of the study is based on the training data set alone. We used the PROSPECT model (Jacquemoud and Baret, 1990) to describe the radiative transfer in the leaf. This model assumes the leaf to be composed of $N$ homogeneous identi- cal layers separated by air spaces. Each layer is characterised by a refraction index and an absorption coefficient $K$. The absorption coefficient is explained as the sum of specific absorption coefficients $(k)$ weighed by the contents of each absorbing material. In our case, since water and dry matter are the only leaf absorbing materials considered, modelling leaf optical properties amounts to estimating the specific absorption coefficients $k_{\mathrm{SLW}}$ and $k_{\mathrm{w}}$ such as:

$$
N \cdot[K]=\left[k_{\mathrm{SLW}}\right] \cdot[\mathrm{SLW}]+\left[k_{\mathrm{w}}\right] \cdot\left[C_{\mathrm{w}}\right]
$$

The product $N .[K]$ takes into account the fact that the absorption coefficient $K$ is associated to a single elementary layer, $N$ being the number of equivalent layers. The $N$ parameter governs leaf scattering, which depends on leaf mesophyll structure. $N$ is thus often termed as the structure index.

In the following, we will first retrieve the absorption coefficient $K$, and then estimate the specific absorption coefficients $k_{\mathrm{SLW}}$ and $k_{\mathrm{w}}$ using the measured contents SLW and $C_{\mathrm{w}}$. The approach used here is very similar to that used in our previous study (Fourty et al, 1996) for the detailed biochemical composition.

\section{Estimation of the absorption coefficient}

The PROSPECT model computes leaf reflectance and transmittance $[\rho(\lambda), \tau(\lambda)]$ as a function of the structure index $(N)$ and the absorption coefficient $K(\lambda)$ :

$$
[\rho(\lambda), \tau(\lambda)]=\operatorname{PROSPECT}(K(\lambda), N)
$$

The refraction index is fixed to the values proposed by Jacquemound and Baret (1990). The PROSPECT model inversion allows us to retrieve the two input variables $K(\lambda)$ and $N$. We used the simplex algorithm (Nelder and Mead, 1965), to estimate concurrently $K(\lambda)$ and $N$ from the measured reflectance and transmittance spectra. This algorithm provides a good compromise between the robustness of the solution and the computing time. The merit function used is the simple qua-

Table I. Minimum, average and maximum values of specific leaf weight and water content.

\begin{tabular}{lccc}
\hline & Minimum & Average & Maximum \\
\hline$C_{\mathrm{w}}$ : water content $(\mathrm{cm})$ & $0.0048-0.0062$ & $0.0120-0.0162$ & $0.0248-0.0467$ \\
SLW: specific leaf weight $\left({\left.\mathrm{g} . \mathrm{cm}^{-2}\right)}^{-}\right.$ & $0.0022-0.0008$ & $0.0050-0.0038$ & $0.0128-0.0083$ \\
\hline
\end{tabular}

Values on the left correspond to the training data set (58 samples), and values on the right to the validation data set (22 samples). 
dratic sum of the residual between measured and estimated spectra of both reflectance and transmittance. The inversion process is performed over each of the 58 samples. Inverting the model over the whole spectra takes a lot of computing time. We therefore decided to invert the model in two steps.

In the first step, the model is inverted over a selection of ten wavelengths (780-820-880-920$1400-1500-2100-2300-2400 \mathrm{~nm}$ ) to provide estimates of $N$ as proposed in Fourty et al (1996). This saves significant computer time while keeping consistent values of $N$ as compared to the inversion performed over the full spectra.

In the second step, we used the previously estimated $\mathrm{N}$ value to invert the model for each wavelength to obtain the spectral variation of the absorption coefficient $K(\lambda)$.

To evaluate the performances of the inversion process, we simulated reflectance and transmittance spectra of the 58 fresh leaves using the retrieved values of the absorption coefficient and structure parameter $N$. The simulated spectra are then compared with the measured spectra (fig 1). The RMSE values associated with the reconstruction of reflectance and transmittance are small, 0.011 and 0.010 , respectively, with high $R^{2}(0.989$ and 0.993 , respectively).

\section{Determination of the specific absorption coefficients for water and dry matter}

The resulting 58 absorption coefficient spectra $K(\lambda)$ and the corresponding specific leaf weight and water content were used to solve equation [1] according to:

$$
\begin{aligned}
& {\left[N .[K]=\left[k_{\mathrm{SLW}}\right] \cdot[\mathrm{SLW}]+\left[k_{\mathrm{w}}\right] \cdot\left[C_{\mathrm{w}}\right]\right.} \\
& \quad=[k] \cdot[C]] \Rightarrow\left[[\mathrm{k}]=N \cdot[K] \cdot[C]^{-1}\right]
\end{aligned}
$$

where the matrix $[k]$ was the matrix of the specific absorption coefficients, and $[C]$ the matrix of the water and dry matter contents. The lack of significative correlation between water and dry matter contents allowed us to invert matrix $[C]$. We used the non-negative linear least square algorithm (Lawson and Hanson, 1974) to constrain the specific absorption coefficients to be positive. We thus avoided physically meaningless negative values.

The specific absorption coefficients estimated for water using our data set had very similar shapes as compared to Curcio and Petty's (1951) values (fig 2). However, our estimated values of
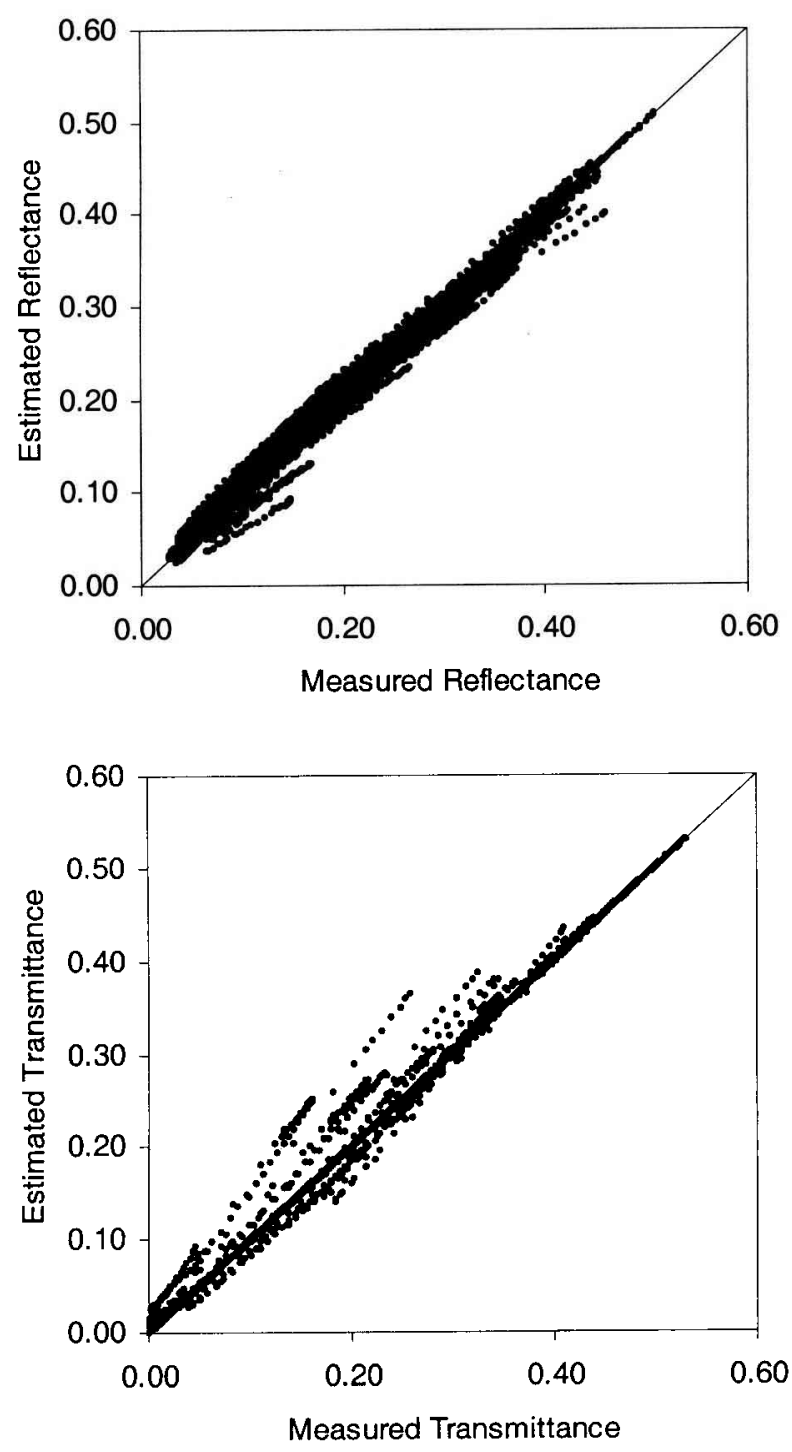

Fig 1. Comparison between the measured leaf reflectance or transmittance and the values simulated using the PROSPECT model and the estimated values of $K(\lambda)$ and $N$. Results obtained on the training data set.

$k_{\mathrm{w}}$ were systematically higher than Curcio and Petty's coefficients. The regression between our estimates and Curcio and Petty's coefficients demonstrated the systematic bias:

$$
\begin{gathered}
k_{\mathrm{w}}=1.12 k_{\mathrm{w}}^{\text {Curcio }} \\
\left(R^{2}=0.993, n=110, \mathrm{RMSE}=3.46 \mathrm{~cm}^{-1}\right)
\end{gathered}
$$

These problems could be due to inaccuracies in the water and radiometric measurements, but also in the modelling of the radiative transfer. In particular, the actual optical path might be different from the one implicitly used in the modelling, since fluxes inside the leaf are assumed to be isotropic. Vogelman (1993) showed that light fluxes within the leaves were not strictly isotropic. 


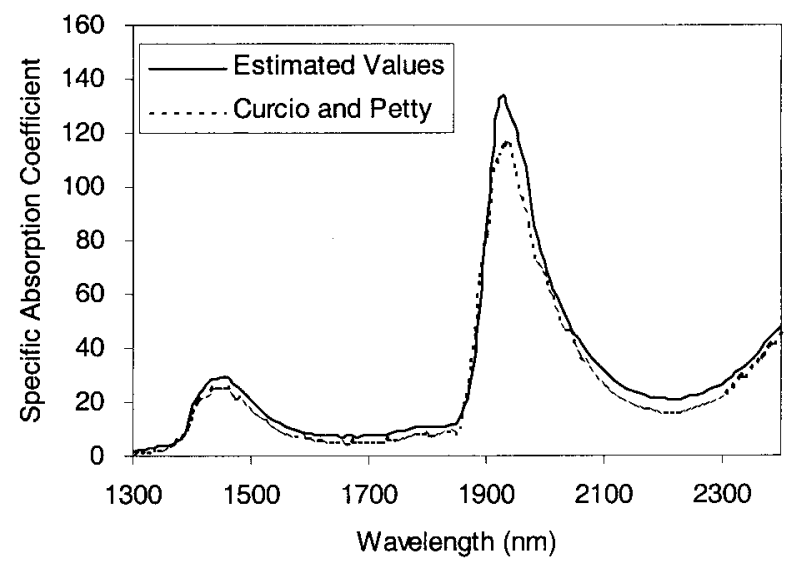

Fig 2. Comparison between the specific absorption coefficients of water $\left(k_{\mathrm{w}}\right)$ given by Curcio and Petty (1951) and that estimated in this study.

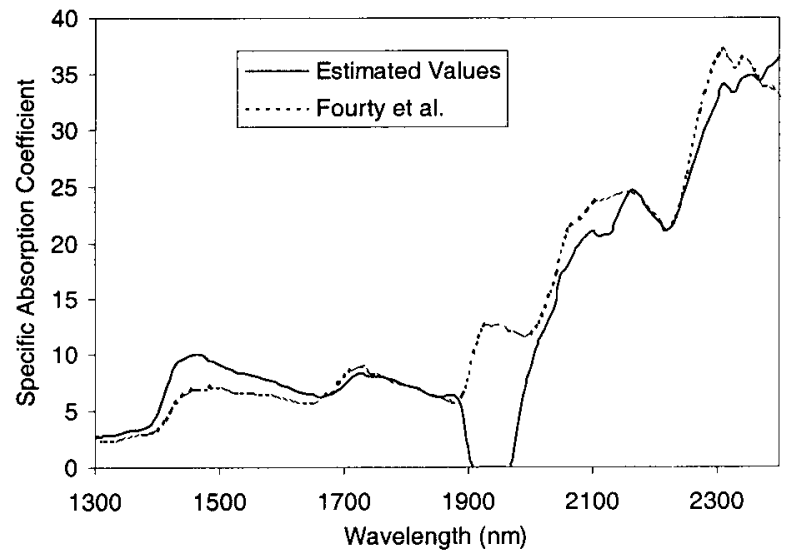

Fig 3. Comparison between specific absorption coefficients of dry matter $\left(k_{\mathrm{SLW}}\right)$ provided by Fourty et al (1996) and the values estimated in this study.

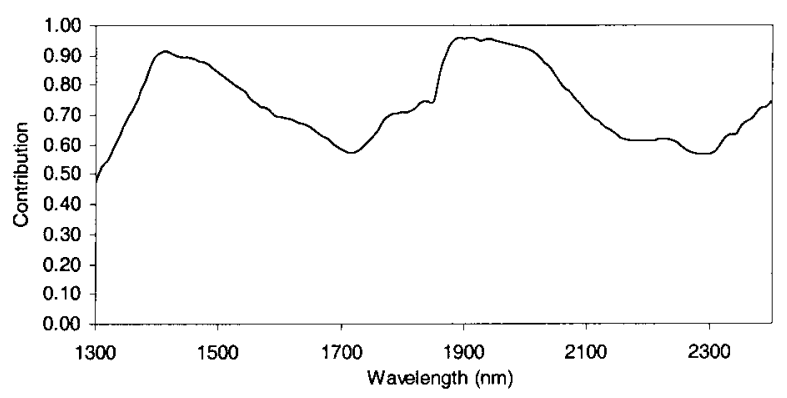

Fig 4. Contribution of the water to the total leaf absorption. The contribution is computed as: $k_{\mathrm{w}}(\lambda) \cdot \overline{C_{\mathrm{w}}} /\left(k_{\mathrm{SLW}}(\lambda) \cdot \overline{\mathrm{SLW}}\right.$ $+k_{\mathrm{w}} \cdot \overline{C_{\mathrm{w}}}$ ) where $\overline{\mathrm{SLW}}$ and $\overline{C_{\mathrm{w}}}$ are the average SLW and $C_{\mathrm{w}}$ values. $k_{\mathrm{w}}$ and $k_{\mathrm{SLW}}$ are, respectively, the specific absorption coefficients proposed by Curcio and Petty (1951) and Fourty et al (1996).
Further, water in the leaf was not at the same temperature as in Curcio and Petty's experiment, and was not pure water because it was in the leaf matrix as a solution. Further, some small fraction of water of constitution should remain after the drying process in the oven.

The corresponding estimated values of the dry matter specific absorption coefficients (fig 3 ) were quite smooth except in the $1900-2$ 000-nm region. A good agreement was observed with values estimated by Fourty et al (1996) over dry leaves except in strong water absorption regions (1 400-1 $600 \mathrm{~nm} ; 1$ 900-2 $000 \mathrm{~nm}$ ). This can be explained by the very small contribution of approximately $10 \%$ of dry matter to the total leaf absorption in these spectral regions (fig 4).

From the comparison between the several ways to obtain the specific absorption coefficients, the best solution was to use Curcio and Petty's coefficients corrected using equation [4] for water, and Fourty et al (1996) coefficients for dry matter. Both values were quite smooth and presented no singularities in the strong water absorption bands.

Once the PROSPECT model was calibrated for taking into account water and dry matter contents, we investigated the performances of model inversion for the retrieval of leaf biochemical composition. This was achieved on the training data set already used along with the specific absorption coefficient for dry matter proposed by Fourty et al (1996), and that for water derived by Curcio and Petty as justified above. Therefore, this 'training' data set was considered as almost independent for the evaluation of water content and specific leaf weight retrieval, since the specific absorption coefficients used in the inversion process were not derived from this data set. Nevertheless, to improve the degree of reliability of the results, we used the additional independent validation data set that was described in the section "Validation data set'.

\section{RETRIEVAL OF SPECIFIC LEAF WEIGHT AND WATER CONTENT}

\section{Retrieval using concurrent measurements of reflectance and transmittance}

The PROSPECT model using Curcio and Petty's (1951) and Fourty et al's (1996) specific absorption coefficients, respectively, was inverted to obtain the fresh leaf water and dry matter content. The inversion was performed concurrently over 
reflectance and transmittance measurements in all the wavelengths from 1300 to $2400 \mathrm{~nm}$ with a $10-\mathrm{nm}$ sampling interval. The inversion process was very similar to that described in the section 'Modelling fresh leaf optical properties', except that equation [1] was solved in SLW and $C_{\mathrm{w}}$ rather than in $k_{\mathrm{SLW}}$ and $k_{\mathrm{w}}$. Here again we used the simplex algorithm for convergence and the same merit function as in the section 'Estimation of the absorption coefficient'. We characterised the retrieval performances by the classical RMSE value that has the same unit as the variable considered.

\section{Water content}

The inversion of the model using Curcio and Petty's specific water absorption coefficient and Fourty's specific absorption coefficient for dry matter provided good estimates of the water content although a slight overestimation in the training data set was observed (table II). When using the proposed correction for Curcio and Petty's specific absorption coefficient, we improved significantly the estimation for the training data set (table II). However, when considering the validation data set, the uncorrected specific absorption coefficient led to better results than the corrected values. When considering the whole data set, the original Curcio and Petty specific absorption coefficients provided slightly better results $($ RMSE $=0.0025)$ than the proposed correction $(\mathrm{RMSE}=0.0027)$. Figure 5 shows that the $1: 1$ line passed almost through the middle of the cloud of data points when the original Curcio and Petty coefficient was used. This result is in good agreement with previous findings of Jacquemoud and Baret (1990) and Jacquemoud et al (1996). The slight overestimation for the training data set, and the slight underestimation for the validation data

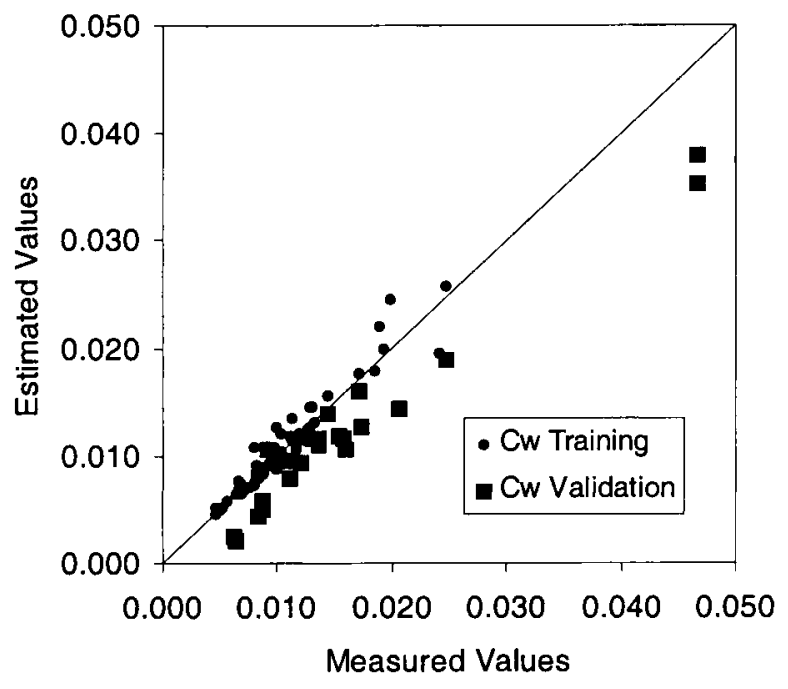

Fig 5. Water $\left(C_{\mathrm{w}}\right)$ contents retrieved from model inversion using concurrently reflectance and transmittance spectra compared to the measured values of $C_{w}$. The solid line is the $1: 1$ line. The training and validation data sets are represented separately.

set were presumably due to subtle differences in the experimental conditions and calibration of the instruments. In the absence of additional data sets that could be used to decide whether to correct the Curcio and Petty absorption coefficient or not, we propose to use the original Curcio and Petty value for the specific absorption coefficient of water. As a matter of fact, it provided the best performances on the validation data set and also on the data set generated by merging the training and the validation data sets.

\section{Specific leaf weight}

Estimates of specific leaf weight were not affected by the correction used for specific water absorption coefficient since this correction was only

Table II. RMSE values characterising the retrieval performances of water content $\left(C_{\mathrm{w}}\right)$ and specific leaf weight (SLW) from concurrent measurements of reflectance and transmittance (Refl and Transmit) or using only reflectance (Refl) or transmittance (Transmit) measurements.

\begin{tabular}{lccc}
\hline & \multicolumn{2}{c}{ Water content $\left(C_{w}\right)$} & \\
\cline { 2 - 4 } & $k_{w}=k_{w}^{\text {Curcio }}$ & $k_{w}=1.12 k_{w}^{\text {Curcio }}$ & $S L W$ \\
\hline Refl and transmit & $0.0022-0.0031$ & $0.0013-0.0046$ & $0.0014-0.0016$ \\
Refl & $0.0022-0.0039$ & $0.0018-0.0053$ & $0.0013-0.0028$ \\
Transmit & $0.0014-0.0041$ & $0.0022-0.0055$ & $0.0010-0.0024$ \\
\hline
\end{tabular}

We used the specific absorption coefficient for water provided by Curcio and Petty ( $k_{\mathrm{w}}=k_{\mathrm{w}}^{\text {Curcio }}$ ) or the one corrected for the optical path $\left(k_{\mathrm{w}}=1.12 k_{\mathrm{w}}^{\mathrm{Curcio}}\right)$ for estimating the water content. Values on the left correspond to the training data set (58 samples), and values on the right to the validation data set (22 samples). SLW: specific leaf weight. 
internal to the water content estimation in the inversion process. The specific leaf weight was accurately estimated from reflectance and transmittance measurements in the $1300-2$ 400-nm spectral domain (fig 6), with an overall RMSE value of 0.0016 . Similarly to the water content, we observed a slight overestimation of the specific leaf weight for the training data set, and an underestimation for the validation data set while the RMSE values associated with the two data sets were close together (table II).

These results demonstrated that inverting the PROSPECT model provided good estimates of water and dry matter contents from fresh leaf reflectance and transmittance measurements over the 1300-2 400-nm spectral range. We then investigated how the inversion behaved when using only reflectance or transmittance measurements. This is of potential interest for the design of a device dedicated to the estimation of leaf water and dry matter contents.

\section{Retrieval performances using reflectance or transmittance.}

The same model inversion procedure was repeated for the retrieval of the water and dry matter contents from the measurements of reflectance and transmittance spectra.

We compared the estimates of the $N$ parameter retrieval when using reflectance and transmittance concurrently to that estimated when using

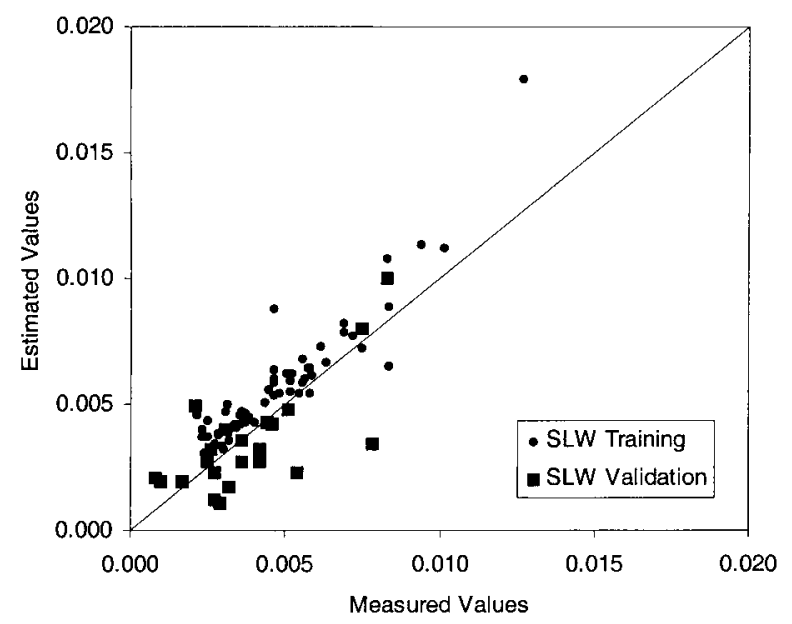

Fig 6. Specific leaf weight (SLW) retrieved from model inversion using concurrently reflectance and transmittance spectra compared to the measured values of SLW. The solid line is the 1:1 line. The training and validation data sets are represented separately. reflectance or transmittance separately. Results showed that the inversion using only reflectance spectra underestimated the $N$ values retrieved when using reflectance and transmittance concurrently (fig 7). Conversely, the $N$ parameter values retrieved using only transmittance were overestimated. This could be explained by the relaxation of the constraints in the inversion process that induced possible compensations between the scattering process governed by the $N$ parameter and the absorption process governed by the adjusted absorption coefficient.

Over the training data set, water and dry matter estimates remained good (table II) when using reflectance or transmittance measurements. However, this was not the case for the validation data set for which the accuracy of the estimation decreased significantly. This was explained by the underestimation observed for the $N$ parameter for reflectance (overestimation for transmittance, respectively) that was compensated for by a decrease in the absorption coefficient leading to a decrease in the water content or specific leaf weight. To resolve the situation for the validation data set, the unbiased estimates observed when using reflectance and transmittance simultaneously, were biased when using either the reflectance or the transmittance in the inversion process.

\section{CONCLUSION}

This study demonstrated that a simple radiative transfer model, the PROSPECT model, could be

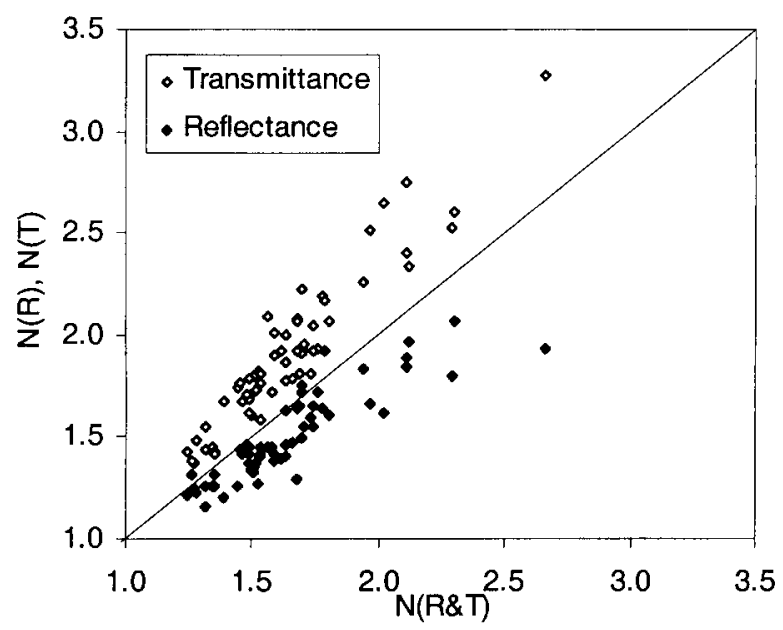

Fig 7. Comparison between the values of the $N$ structure parameter retrieved from model inversion using concurrently reflectance and transmittance $(N(R \& T))$ and those retrieved using from inversion using either reflectance $(N(R))$ or transmittance $(N(T))$. The solid line is the 1:1 line. Results obtained on the training data set. 
used to simulate accurately fresh leaf reflectance and transmittance in the 1300-2 400-nm spectral domain using as inputs three variables: the $N$ structure index, which characterises the scattering within leaf internal structure, water $\left(C_{\mathrm{w}}\right)$ and dry matter (SLW) contents. This confirmed the conclusion of our previous study performed over dry leaves: the contribution of each individual biochemical compound is not strong enough and not sufficiently well defined to significantly improve the accuracy of reflectance or transmittance computations. Such a model could be used to more accurately describe leaf optical properties in the computation of canopy radiative transfer, both for remote sensing and canopy functioning applications.

We estimated the specific absorption coefficients for water and dry matter over a wide range of fresh leaves. For dry matter, the values retrieved were in good agreement with values proposed by Fourty et al (1996) except in the water absorption bands. This was explained by the important contribution of water to the leaf absorption as compared to that of the dry matter. We thus proposed to use the specific absorption coefficient estimated by Fourty et al (1996) that was derived from dry leaf measurements. For characterising water absorption we proposed to use Curcio and Petty (1951) specific absorption coefficient for pure water.

Inversion of the PROSPECT model using reflectance and transmittance measurements concurrently provided good estimates of water content and leaf specific weight. These conclusions might be considered as robust because of the physical nature of the model used, the large range of leaf characteristics observed in the data set, and the fact that the specific absorption coefficients used derived from independent studies. Water content and specific leaf weight are both important variables involved in many physical and physiological processes. Thus, future applications of these findings could be investigated. For remote sensing applications, we should determine if water and dry matter content retrieval is possible from reflectance measurements performed over canopies. This could drive the design of future space missions dedicated to the monitoring of vegetation. Another potential application is the measurement in situ of leaf water content and specific weight. We compared the accuracy of the estimation when using either the reflectance or the transmittance in the inversion process. Results showed that it is recommended to use reflectance and transmittance measurements concurrently to better constrain the inversion of the model and obtain more accurate and unbiased estimates of $C_{\mathrm{W}}$ and SLW. Further work is required to investigate the possibility of developing a special procedure providing similar precision in the estimation of $C_{\mathrm{W}}$ and SLW, but using only reflectance or transmittance measurements.

Acknowledgments: We thank the agencies that funded this study: European Space Agency under the 'Plant canopy biochemistry' contract 10661/93/NL/SF, Centre national de la recherche spatiale (France), and National Aeronautic and Space Administration through the LEAF MOD project. We thank also S Jacquemoud, G Schmuck, J Verdebout, G Andreoli, B Hoosgood, A Pedrini and SE Horning from the Joint Research Centre at Ispra (Italy) for kindly providing the Lopex data set used in this study.

\section{REFERENCES}

Allen WA, Gausman HW, Richardson AJ, Thomas JR (1969) Interaction of isotropic light with a compact plant leaf. J Opt Soc Am 59, 1376-1379

Beaumont P (1995) Reflectance foliaire et acclimatation a un deficit hydrique : cas des feuilles de tournesol. Universté Paul-Sabatier, Toulouse, 129 p

Curcio JA, Petty CC (1951) The near infrared absorption spectrum of liquid water. I Opt Soc Am 41, 302304

Curran PJ, Kupiec JA, Smith G (1997) Remote sensing the biochemical composition of a slash pine canopy. IEEE Trans Geosci Remote Sens 35, 415-420

Field C, Mooney HA (1986) The PhotosynthesisNitrogen Relationship in Wild Plants. On the Economy of Plant Form and Function (TV Givnich, ed), Cambridge Univ Press, New York, USA, 25-55

Fourty T, Baret F, Jacquemoud S, Verdebout J (1996) Leaf optical properties with explicite description of its biochemical composition: direct and inverse problems. Remote Sens Environ. 56, 104-117

Gastellu-Etchegorry JP, Zagolski F, Mougin E, Marty G (1995) Assessment of canopy chemistry using AVIRIS. A case study in the Landes, south-west of France. Int J Remote Sens 16, 487-501

Gholz HL, Curran PJ, Kupiec JA, Smith GM (1996) Assessing leaf area and canopy biochemistry of Florida pine plantations using remote sensing. In: The Use of Remote Sensing in the Modeling of Forest Productivity (HL Gholz, K Nakane, H Shimoda, eds), Kluwer Acad Publ, Dordrecht, the Netherlands, 3-22

Grossman YL, Ustin SL, Jacquemoud S, Sanderson E, Schmuck G, Verdebout J (1996) Critique of stepwise linear regression for the extraction of leaf biochemistry information from leaf reflectance data. Remote Sens Environ 56, 182-193

Hosgood BS, Jacquemoud S, Andreoli G, Verdebout J, Pedrini G, Schmuck G (1995) Leaf optical proper- 
ties experiment 93 (LOPEX93). Ispra (Italy), European Commission, Joint Research Center, Institute of Remote Sensing Applications

Hunt ER, Rock BN (1989) Detection of changes in leaf water content using near and middle-infrared reflectances. Remote Sens Environ 30, 43-54

Hunt ER, Rock BN, Nobel PS (1987) Measurement of leaf relative water content by infrared reflectance. Remote Sens Environ 22, 429-435

Jacquemoud S, Baret F (1990) PROSPECT: A model of leaf optical properties spectra. Remote Sens Environ 34, 75-91

Jacquemoud SS, Ustin L, Schmuck G, Andreoli G, Hosgood B (1996) Estimating leaf biochemistry using the PROSPECT leaf optical properties model. Remote Sens Environ 56, 194-202

Lawson CL, Hanson RJ (1974) Solving Least Squares Problems. Prentice-Hall.

Martin ME, Aber JD (1993) Measurements of canopy chemistry with AVIRIS data at blackhawk island and Harvard forest. 4th JPL Airborne Geoscience Workshop, JPL Publication, Pasadena, CA

Martin ME, Aber JD (1994) High spectral resolution remote sensing of canopy chemistry. International symposium of the ISPRS, Val d'Isère (France), CNES. 201-208
NASA (1994) Accelerated canopy chemistry program. Final report to NASA-EOS-IWG. Washington (DC), NASA

Nelder JA, Mead RA (1965) A simplex method for function optimization. Comput J 7, 308-313

Peterson DL, Aber JD, Matson PA, Card DH, Swanberg N, Wessman C, Spanner M (1988) Remote sensing of forest canopy and leaf biochemical contents. Remote Sens Environ 24, 85-108

Smith GM, Curran PJ (1992) Exploring the remote sensing of foliar biochemical concentrations with AVIRIS data. 3rd JPL airborne geoscience workshop, JPL Publication, Pasadena, CA

Thomas JR, Namken LN, Oerther GF, Brown RG (1971) Estimating leaf water content by reflectance measurements. Agron J 63, 845-847

Tucker CJ (1980) Remote sensing of leaf water content in the near infrared. Remote Sens Environ 10, 23-32

Vogelman TC (1993) Plant tissue optics. Annu Rev Plant Physiol Mol Biol 44, 231-251

Wessman CA, Aber JD, Peterson DL, Melillo JM (1988) Foliar analysis using near infrared reflectance spectroscopy. Can J For Res 18, 6-11

Zagolsky F (1994) Évaluation des concentrations chimiques d'un couvert forestier à partir de la haute résolution spectrale. Université Paul-Sabatier, Toulouse, $155 \mathrm{p}$ 